\title{
Carcinoid heart disease revealed by cyanosis with both right and left valvular involvement: a case report
}

\author{
Khadija Khay, Salim Arous*, Tarik Bentaoune, Abdenasser Drighil and Rachida Habbal
}

\begin{abstract}
Background: Carcinoid heart disease is a frequent complication of carcinoid syndrome. It is related to the release by the carcinoid tumor and/or its metastases of bioactive substances such as serotonin. It is characterized by right-sided valvular involvement and can lead to right-sided heart failure. It is a prognostic factor of carcinoid syndrome.

Case presentation: We report the case of a 53-year-old African woman with an endocrine tumor of her small intestine complicated by carcinoid heart disease, revealed by right-sided heart failure. The diagnosis was confirmed by transthoracic echocardiography, which showed a severe tricuspid regurgitation with a patent foramen ovale, and by increased serum chromogranin A and urinary 5-hydroxyindoleacetic acid. Initially she was treated with medical therapy (furosemide and injection of somatostatin). Afterwards she was proposed for surgery. The evolution of her treatment was good.

Conclusions: Carcinoid syndrome is complicated in $60 \%$ of the cases of a heart disease, and is responsible for an important morbidity and mortality. The prognosis of patients with carcinoid heart disease has improved in recent years through somatostatin analogues and the cardiac surgery.
\end{abstract}

Keywords: Carcinoid syndrome, Fibrosis, Carcinoid tumors, Cardiac surgery

\section{Background}

Well-differentiated neuroendocrine tumors are rare. They are characterized by the secretion of a vasoactive substance (serotonin), responsible for the appearance of carcinoid syndrome symptoms (flushing, diarrhea, and bronchoconstriction) $[1,2]$. The direct action of these vasoactive substances on the heart leads to carcinoid heart disease (CaHD; Hedinger's syndrome), which is a frequent complication of carcinoid syndrome; CaHD can be the first presentation of carcinoid syndrome in up to $20 \%$ of patients. Right-sided heart failure is a prognostic factor of carcinoid syndrome [3].

The management of CaHD is based on medical therapy (somatostatin analogues), resection of the primary tumor, and cardiac interventions. Surgical valve replacement is an effective treatment option for symptomatic patients, since it improves the symptoms and life quality [4].

\footnotetext{
* Correspondence: Arous.salim@hotmail.fr

Department of Cardiology, Ibn Rushd University Hospital, Casablanca, Morocco
}

(c) The Author(s). 2018 Open Access This article is distributed under the terms of the Creative Commons Attribution 4.0 International License (http://creativecommons.org/licenses/by/4.0/), which permits unrestricted use, distribution, and reproduction in any medium, provided you give appropriate credit to the original author(s) and the source, provide a link to the Creative Commons license, and indicate if changes were made. The Creative Commons Public Domain Dedication waiver (http://creativecommons.org/publicdomain/zero/1.0/) applies to the data made available in this article, unless otherwise stated.
Through the case of a 53-year-old woman with an endocrine tumor complicated by CaHD, we will discuss carcinoid syndrome and the peculiarities of cardiac involvement. In particular, in this case, we noted the involvement of both the left-sided and right-sided heart, which is rare during carcinoid syndrome. This is related to the presence of a communication between the right and left cavities of her

\section{Case presentation}

A 53-year-old African woman presented with heart failure with increasing dyspnea, lower limb edema, and cyanosis of her lips and extremities with refractory hypoxia. We noted that she did not have a history of heart disease or digestive pathology. She was never operated on previously, and had no history of medical pathology or surgery in her family.

A clinical examination revealed blood pressure of 120/70 $\mathrm{mmHg}$, oxygen saturation at $85 \%$, and a $3 / 6$ diastolic murmur of aortic insufficiency with a holosystolic murmur (grade 4/6) suggestive of tricuspid valve regurgitation. Lower limb edema up to her knee joint was also present. We also heart, which explains her severe hypoxia and cyanosis. 
detected a flushing with hepatalgia and asthenia. A neurological examination was normal; in particular, there was no sensory or motor deficit and no language disorder. The rest of the clinical examination was also normal.

A 12-lead electrocardiogram (ECG) showed sinus rhythm and a heart rate of 66 beats per minute (bpm; Fig. 1).

She underwent transthoracic echocardiography, which showed slightly dilated right heart cavities with right ventricular end diastolic diameter (RVEDD)/left ventricular end diastolic diameter (LVEDD) of 0.8, right atrial (RA) area of $20 \mathrm{~cm}^{2}$, and tricuspid ring of $39 \mathrm{~mm}$ with a preserved function in which tricuspid annular plane systolic excursion (TAPSE) was $16 \mathrm{~mm}$ and right ventricular (RV) velocity $\left(S^{\prime}\right)=10 \mathrm{~cm} /$ second. Tricuspid valves appeared thickened and retracted with restricted mobility and poor coaptation responsible for a severe tricuspid regurgitation (Figs. 2 and 3). Pulmonary valves were thickened with a moderate pulmonary (IP) insufficiency.

A large patent foramen ovale (PFO) with aneurysm of her interatrial septum was detected with continuous right-to-left shunting (Fig. 4).

The left-sided valves were not normal (Fig. 5). Our patient had a moderate aortic regurgitation and minimal mitral insufficiency. The function of the left ventricle was good with ejection fraction (EF) of $55 \%$.

She was initially treated with furosemide. The evolution of her treatment was marked by regression of the signs of her heart failure.

Because of her hepatalgia, a computed tomography (CT) of her abdomen was done and showed multiple hepatic and mesenteric nodules. A resection of $30 \mathrm{~cm}$ of her small bowel was done with an anterior gastrointestinal anastomosis.

Biopsies of her liver and mesenteric nodules showed a secondary mesenteric and hepatic localization of a welldifferentiated endocrine carcinoma. An immunohistochemical study showed positivity for chromogranin and negativity for synaptophysin. Laboratory findings revealed increased serum chromogranin A $(574 \mathrm{ng} / \mathrm{ml}$, normal < $102 \mathrm{ng} / \mathrm{ml}$ ) and urinary 5-hydroxyindoleacetic acid (5HIAA; $1183 \mu \mathrm{mol} / 24$ hours, normal $<40 \mu \mathrm{mol} / 24$ hours). An octreotide scan showed an intense radiotracer accumulation in her liver as well as normal distribution of the radiotracer in her kidneys and spleen (Fig. 6).

Because of all these elements, we concluded that our patient had carcinoid syndrome complicated by the involvement of both the right side and left side of her heart. Her cyanosis was due to a right-to-left cardiac shunt.

Our patient received somatostatin analogue therapy (one injection every 3 weeks). Her 5-HIAA and chromogranin A levels decreased to $450 \mu \mathrm{mol} / 24$ hours and $109 \mathrm{ng} / \mathrm{ml}$ respectively. For the heart disease, cardiac surgery was indicated: foramen ovale closure with tricuspid valve plasty.

The evolution of her treatment was marked 6 months after the surgical procedure by the regression of hypoxia with good clinical improvement. An echocardiography control showed minimal tricuspid regurgitation, without residual shunt of patent foramen oval.

\section{Discussion}

Carcinoid syndrome is a paraneoplastic syndrome mediated by humoral factors released by some carcinoid tumors. The

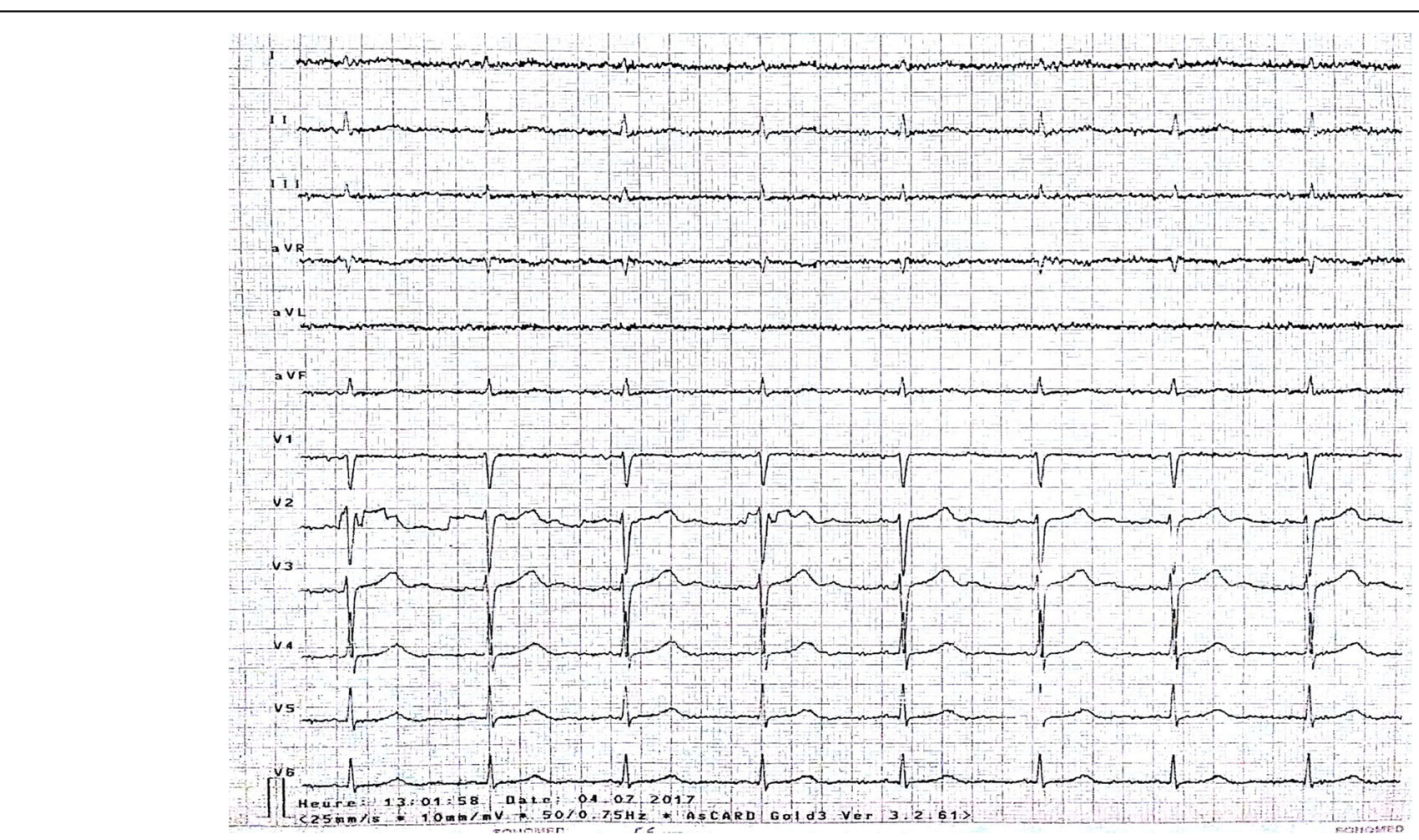

Fig. 1 An electrocardiogram of our patient showing no abnormality 


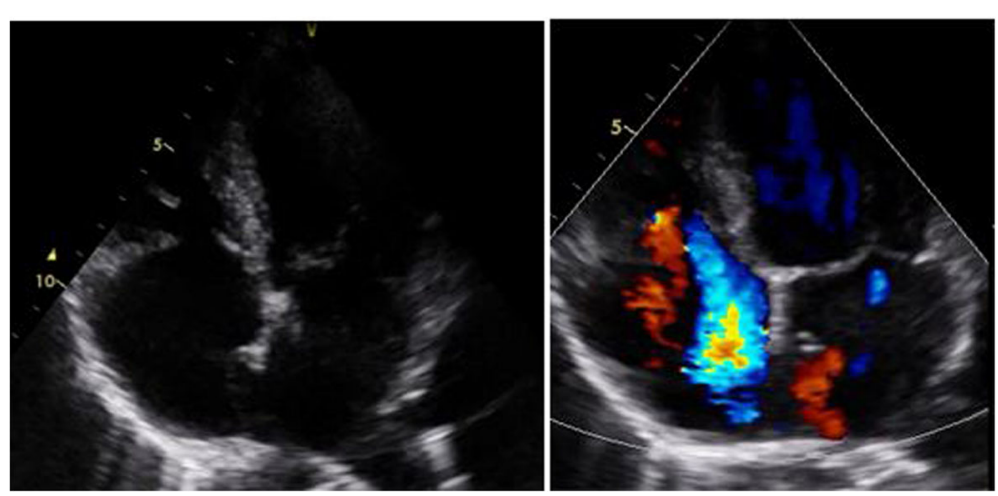

Fig. 2 Transthoracic echocardiogram apical four-chamber view showed thickened and retracted tricuspid valves with significant regurgitation and patent foramen ovale

majority of neuroendocrine tumors arise from the small intestine, particularly in the ileum, and they release into the systemic circulation a variety of vasoactive substances: serotonin, 5-hydroxytryptamine, 5-hydroxytryptophan, histamine, tachykinins, bradykinin, and prostaglandins, which explain the clinical manifestations of carcinoid syndrome [2].

Carcinoid syndrome is rare and once it is developed, more than $50 \%$ of the patients develop CaHD that can inaugurate this syndrome in $20 \%$ of cases. It is associated with a poor prognosis [3].

Symptoms of carcinoid syndrome (facial flushing, hypermotility of the gastrointestinal system, bronchoconstriction, and hypotension) usually occur in patients with hepatic metastatic lesions, due to the lack of hepatic inactivation of these released hormones [5].

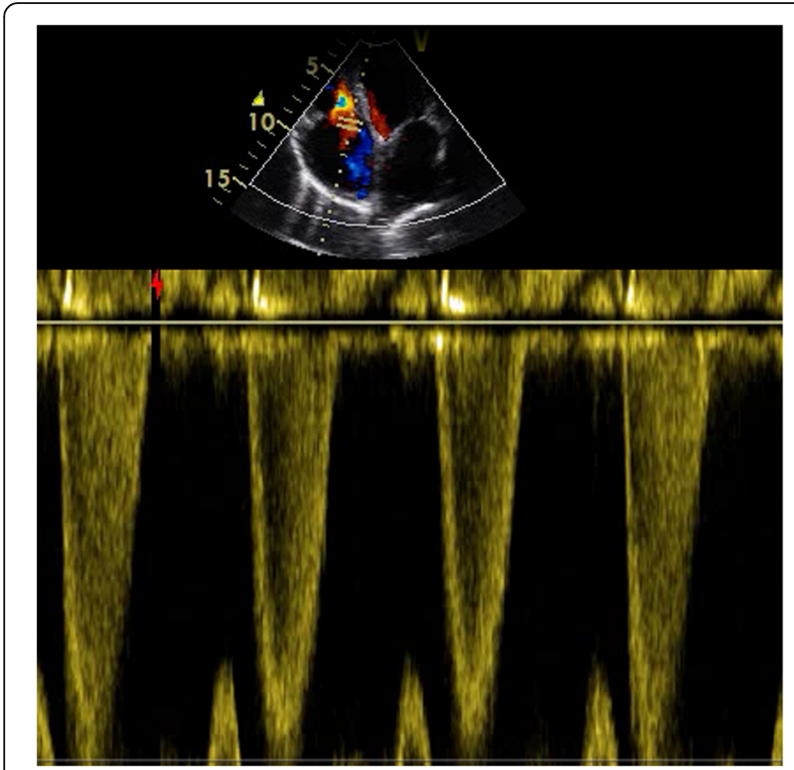

Fig. 3 Doppler interrogation of tricuspid regurgitation showing laminar tricuspid insufficiency
These vasoactive substances act directly on the valvular endocardium and activate a fibrotic process. Histopathology reveals fibrous plaque-like and endocardial thickening leading to thickening and retraction of the valves. In this disease, the involvement of the right-sided heart valves is predominant and may be in the form of regurgitation and/or stenosis [6, 7]. Right-sided heart failure remains a major factor of morbidity in patients with CaHD [8]. Left-sided cardiac involvement is rarely observed $(<10 \%$ of patients), particularly in the case of right-to-left shunt (a PFO) or bronchial carcinoids due to the bypassing of inactivation of serotonin within the lung [9].

The diagnosis is essentially based on biological examinations and echocardiography which remains the principal imaging modality in assessment of CaHD [6-10]. Biological examinations are helpful in the diagnosis of $\mathrm{CaHD}$. High levels of $\mathrm{N}$-terminal pro-brain natriuretic peptide (NT-proBNP), chromogranin-A (a neuroendocrine secretory protein), and urinary 5-HIAA (a metabolite of serotonin) are correlated with the progression of CaHD [11, 12]. Echocardiography shows typical valvular involvement: the tricuspid valve is constantly thickened, rigid, and retracted with restricted mobility and poor coaptation which lead to tricuspid regurgitation. Stenosing character is rarer (25\% of cases) but may be associated. The pulmonary valve, which is more difficult to study, is reached in $30 \%$ of cases with regurgitation or pulmonary stenosis [10-13].

The right cavities and the inferior vena cava are dilated with or without right ventricular dysfunction [14]. Myocardial strain allows detection of an early right ventricular dysfunction in patients with CaHD independently of valvular involvement [15].

Of all patients with $\mathrm{CaHD}, \leq 10 \%$ have lesions of the left-side valve. CaHD in the left side of the heart is less severe than in the right side of the heart. Leftsided heart involvement in carcinoid syndrome happens 


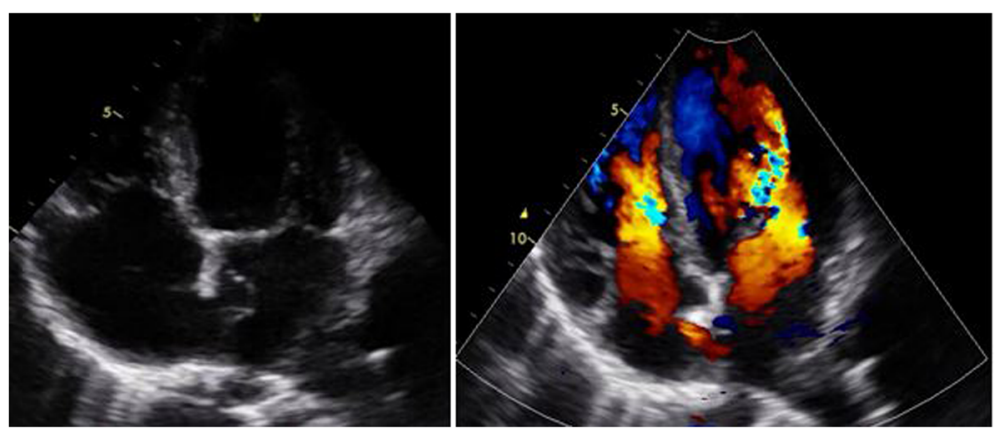

Fig. 4 Patent foramen ovale with continuous shunting

in patients with persistent foramen ovale or bronchial carcinoid [16].

Patients with CaHD have a decreased life expectancy compared with patients without cardiac lesions [17]. The treatment of patients with carcinoid syndrome is complex and involves multidisciplinary management. It is based on medical therapy, surgery of the tumor, and cardiac surgery [2].

Medical management consists of controlling the heart failure (diuretics agents and aldosterone antagonist) and symptoms of carcinoid syndrome. Therapy by somatostatin analogues allows improvement of symptoms and quality of life and decreases the incidence of CaHD from 50 to 20\% [4].

New agents (telotristat and pasireotide) have shown promising results in patients with carcinoid syndrome refractory to somatostatin analogues [18]. Telotristat etiprate is a potent inhibitor of the synthesis of serotonin. The phase III TELESTAR clinical trial has shown

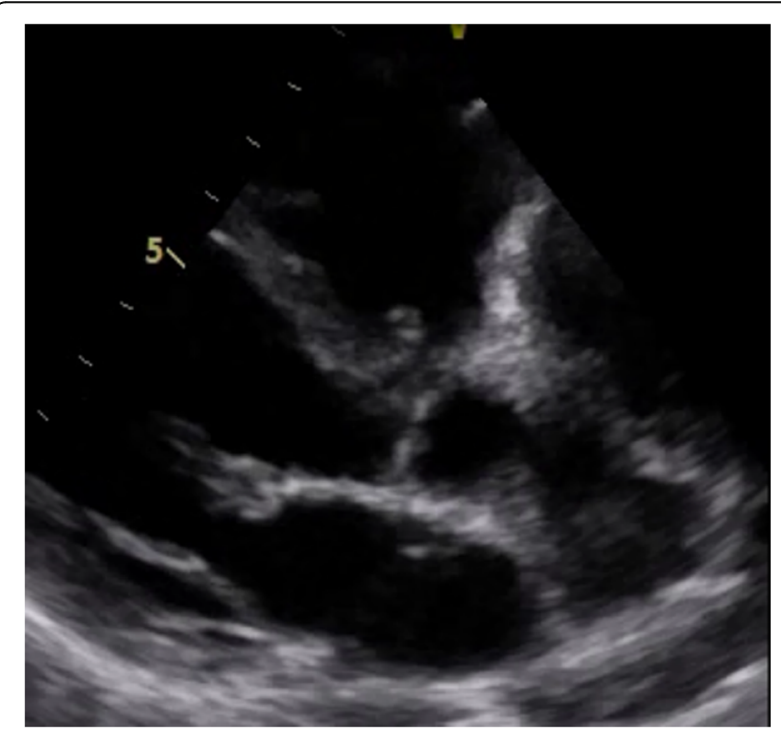

Fig. 5 Parasternal long-axis view showed thickened left-sided valves that Telotristat may control the bowel movements in patients with carcinoid syndrome. It represents a new option for the treatment of patients with refractory carcinoid syndrome. However, other research is required to verify the safety and the benefit to control symptoms of that new drug [19].

Interferon alpha can be used as a complementary treatment for somatostatin analogues in refractory carcinoid syndrome. Because of its side effects, it should be initiated by $3 \mathrm{MU}$ thrice weekly and then an individual titration [20].

Surgical resection of the primary tumor and resection of liver metastases appear to decrease the cardiac progression in CaHD and improve prognosis [16]. Since hepatic surgery exposes a patient to the risk of perioperative bleeding, hepatic intra-arterial treatment (transarterial chemoembolization, selective internal radiotherapy) is well suited to patients with hepatic metastases [21].

Valve replacement surgery or valvuloplasty is the only effective treatment for symptomatic CaHD; it improves the symptoms and increases the life expectancy of these patients [22]. The optimal moment for valve replacement surgery is not established. However, valvular surgery is proposed when patients become symptomatic or develop ventricular dysfunction provided they have a life expectancy of at least 1 year [20]. Bioprosthetic valves are generally preferred over a mechanical prosthesis, which requires anticoagulation for life and then exposes patients with liver metastases to the risk of bleeding in addition to the risk of prosthesis thrombosis in tricuspid position [23]. Percutaneous valve implantation is a novel option in high-risk patients with severe CaHD, who have poor performance status and comorbidities that do not allow open surgery [24].

The prognosis of patients with CaHD has improved in recent years through cardiac surgery. In the Mayo Clinic, a retrospective analysis of 200 patients with CaHD found that cardiac surgery improves the prognosis and reduced the mortality related to that disease $[25,26]$. 


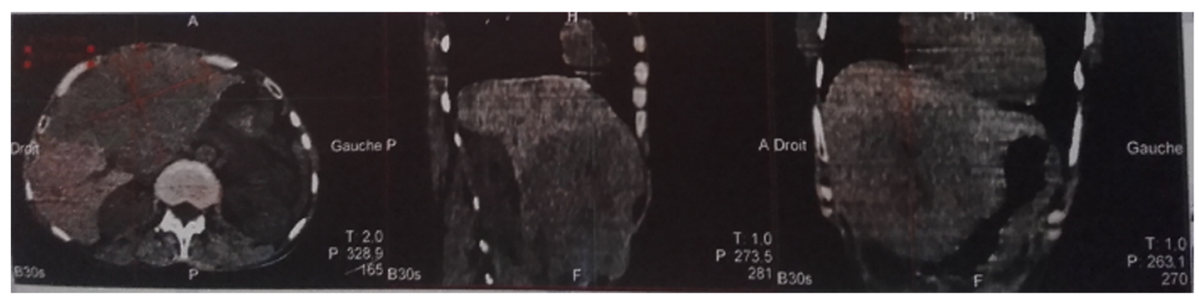

Fig. 6 Octreotide scan showing two areas of radiotracer accumulation

\section{Conclusions}

Carcinoid syndrome is rare and can lead to heart failure, which then interferes with the quality of life of these patients. Echocardiography is recommended to evaluate the cardiac involvement in patients with carcinoid syndrome. Surgical valve replacement can improve the clinical outcome and the prognosis of patients with CaHD.

\section{Acknowledgements}

Not applicable.

\section{Funding}

The authors have no funding to declare.

\section{Availability of data and materials}

The published information is available from the corresponding author on reasonable request.

\section{Authors' contributions}

KK participated in the design of the study, acquired data, performed a literature review, and drafted the manuscript. SA conceived the study, participated in its design and coordination, acquired data, and helped to draft and edit the manuscript. TB participated in the design of the study and edited the manuscript. $\mathrm{RH}$ acquired data, participated in the design of the study, and edited the manuscript. All authors read and approved the final manuscript.

\section{Ethics approval and consent to participate}

The need for ethics approval was waived.

\section{Consent for publication}

Written informed consent was obtained from the patient for publication of this case report and any accompanying images. A copy of the written consent is available for review by the Editor-in-Chief of this journal.

\section{Competing interests}

The authors declare that they have no competing interests.

\section{Publisher's Note}

Springer Nature remains neutral with regard to jurisdictional claims in published maps and institutional affiliations.

Received: 28 October 2017 Accepted: 15 January 2018 Published online: 31 January 2018

\section{References}

1. Yao JC, Hassan M, Phan A, et al. One hundred years after 'carcinoid': Epidemiology of and prognostic factors for neuroendocrine tumors in 35,825 cases in the United States. J Clin Oncol. 2008;26:3063-72.

2. Grozinsky-Glasberg $S$, Grossman AB, Gross DJ. Carcinoid heart disease: from pathophysiology to treatment - 'something in the way it moves'. Neuroendocrinology. 2015;101:263-73.

3. Hassan SA, Banchs J, lliescu C, Dasari A, Lopez-Mattei J, Yusuf SW. Carcinoid heart disease. Heart. 2017;103:1488-95.
4. Bhattacharyya S, Toumpanakis C, Chilkunda D, et al. Risk factors for the development and progression of carcinoid heart disease. Am J Cardiol. 2011:107:1221-6.

5. Bertin N, Favretto S, Pelizzo F, et al. Carcinoid Heart Disease: Starting From Heart Failure. J Investig Med High Impact Case Rep. 2017;5(2). https://doi. org/10.1177/2324709617713511.

6. Pellikka PA, Tajik AJ, Khandheria BK, et al. Carcinoid heart disease. Clinical and echocardiographic spectrum in 74 patients. Circulation. 1993;87:1188-96.

7. Pandya UH, Pellikka PA, Enriquez-Sarano M, et al. Metastatic carcinoid tumor to the heart: Echocardiographic-pathologic study of 11 patients. J Am Coll Cardiol. 2002;40:1328-32.

8. Dero I, De Pauw M, Borbath I, et al. Carcinoid heart disease-a hidden complication of neuroendocrine tumours. Acta Gastroenterol Belg. 2009; 72(1):34-8.

9. Palaniswamy C, Frishman WH, Aronow WS. Carcinoid Heart Disease. Cardiol Rev. 2012;20(4):167-76

10. Plöckinger U, Gustafsson B, Ivan D, et al. ENETS consensus quidelines for the standards of care in neuroendocrine tumors: Echocardiography. Neuroendocrinology. 2009;90:190-3.

11. Bhattacharyya S, Toumpanakis C, Caplin ME, et al. Usefulness of Nterminal pro-brain Natriuretic peptide as a Biomarker of the presence of Carcinoid heart disease. Am J Cardiol. 2008;102:938-42.

12. Bhattacharyya S, Toumpanakis C, Caplin ME, et al. Analysis of 150 patients with carcinoid syndrome seen in a single year at one institution in the first decade of the twenty-first century. Am J Cardiol. 2008;101:378-81.

13. Luis SA, Pellikka PA. Carcinoid heart disease: diagnosis and management. Best Pract Res Clin Endocrinol Metab. 2016;30:149-58.

14. Poyet $R$, et al. Right ventricular failure as the presenting manifestation of a carcinoid syndrome. Rev Med Interne. 2009;30:81-4.

15. Haugaa KH, Bergestuen DS, Sahakyan LG, et al. Evaluation of right ventricular dysfunction by myocardial strain echocardiography in patients with intestinal carcinoid disease. J Am Soc Echocardiogr. 2011;24:644-50.

16. Hart EA, Meijs TA, Meijer RCA, et al. Carcinoid heart disease: a guide for screening and timing of surgical intervention. Neth Hear J. 2017;25(9):471-8.

17. Dobson R, Burgess Ml, Pritchard DM, et al. The clinical presentation and management of carcinoid heart disease. Int J Cardiol. 2014;173:29-32.

18. Wolin EM, Jarzab B, Eriksson B, et al. Phase III study of pasireotide long-acting release in patients with metastatic neuroendocrine tumors and carcinoid symptoms refractory to available somatostatin analogues. Drug Des Devel Ther. 2015;9:5075-86.

19. Molina-Cerrillo J, Alonso-Gordoa T, Martínez-Sáez O, et al. Inhibition of Peripheral Synthesis of Serotonin as a New Target in Neuroendocrine Tumors. Oncologist. 2016;21(6):701-7.

20. Davar J, Connolly HM, Caplin ME, et al. Diagnosing and managing carcinoid heart disease in patients with neuroendocrine tumors: an expert statement. J Am Coll Cardiol. 2017;69(10):1288-304.

21. Kunz PL. Carcinoid and neuroendocrine tumors: building on success. J Clin Oncol. 2015;33:1855-63.

22. Edwards NC, Yuan M, Nolan $\mathrm{O}$, et al. Effect of valvular surgery in carcinoid heart disease: An observational cohort study. J Clin Endocrinol Metab. 2016;101:183-90.

23. Raja SG, Bhattacharyya S, Davar J, et al. Surgery for carcinoid heart disease: current outcomes, concerns and controversies. Future Cardiol. 2010;6:647-55.

24. Laule M, Pschowski R, Pape UF, et al. Staged catheter-based valve treatment of severe carcinoid heart disease. Neuroendocrinology. 2016;103:259-62. 
25. Møller JE, et al. Prognosis of carcinoid heart disease: analysis of 200 cases over two decades. Circulation. 2005;112(21):3320-7. https://doi.org/10.1161/ CIRCULATIONAHA.105.553750.

26. Mota JM, Sousa LG, Riechelmann RP. Complications from carcinoid syndrome: review of the current evidence. Ecancermedicalscience. 2016;10:1-17.

Submit your next manuscript to BioMed Central and we will help you at every step:

- We accept pre-submission inquiries

- Our selector tool helps you to find the most relevant journal

- We provide round the clock customer support

- Convenient online submission

- Thorough peer review

- Inclusion in PubMed and all major indexing services

- Maximum visibility for your research

Submit your manuscript at www.biomedcentral.com/submit 